\title{
Category Scores for Selecting the Most Desirable Options in a Learning Setting
}

\author{
S. Encheva \\ Stord/Haugesund University College \\ Bjørnsonsg \\ Haugesund, Norway
}

\begin{abstract}
Learners' preferences play significant role in effectiveness of a study process. Individual preferences and group preferences however may differ considerably. While data is collected from single users, general settings are usually made to serve groups of people. An approach for incorporating individual preferences into a system serving a number of users is addressed in this work.
\end{abstract}

Keywords-inconsistencies; kansei engineering; rough set

\section{INTRODUCTION}

Kansei data consist of human evaluations and as such is often imprecise and ambiguous, [8]. Examples can be found in studies within car production [5], mobile phones [10], digital cameras [2] and elderly people care equipment [6]. Consumers' preferences are emphised by the category values of a design element in terms of the total Kansei rating score, [11].

Apparently, a category score refers to the mean value of Kansei ratings attained by the said category value. In other words, it indicates the importance of a category value with respect to the Kansei rating scores. For example, a category value with a higher score is more preferred by consumers in the design of a product and more likely to evoke the Kansei being considered. Conversely, a category value with a lower score is less preferred by consumers and, hence, less likely to evoke the Kansei of interest. Thus, a comparison among the category scores attained can possibly reveal the semantic correlations of the condition and decision parts of the Kansei information table and, as a result, the dominance principle can be established.

Category scores happen to be quite handy while sorting inconsistencies induced by violation of dominance principles. Two types of inconsistencies are considered in [10]: Type I inconsistency caused by indiscernibility relations. It occurs when for example two people choose the same values for all conditional attributes but they differ while in the choices of value for decision attributes. Type II inconsistency is due to the violation of dominance principles, f. ex. higher or equal values for all conditional attributes but lower values for for decision attributes. The classical rough set theory can be used to detect and deal with Type I inconsistency only. Detection of Type II inconsistencies however requires application of dominance principles.

Learners' preferences play significant role in effectiveness of a study process. Individual preferences and group preferences however may differ considerably. While data is collected from single users, general settings are usually made to serve groups of people. An approach for incorporating individual preferences into a system serving a number of users is addressed in this work.

\section{BACKGROUND}

In order to discern the preference order of category values associated with a design element, a concept termed category score is defined in [11]:

$$
\operatorname{Score}_{A t t}(\text { Cat })=\frac{1}{N} \sum D_{A t t}(\text { Cat })
$$

Where $\mathrm{D}_{\mathrm{Att}}(\mathrm{Cat})$ is the decision class value (Kansei rating score) of an observation in which the condition attribute (design element) Att takes the category value Cat, and $\mathrm{N}$ is the total number of such observations on the Kansei information table. An interval pattern is a vector of intervals. For more details and definitions see [4].

Two very interesting problems are considered in [1], namely the problem of determining a consensus from a group of orderings and the problem of making statistically significant statements about ordering.

A relation $I$ is an indifference relation when given AIB neither $\mathrm{A}>\mathrm{B}$ nor $\mathrm{A}<\mathrm{B}$ has place in the componentwise ordering. A partial ordering whose indifference relation is transitive is called a weak ordering. A total ordering is a binary relation who is transitive, antisymmetric, and total $(\mathrm{p} \leq \mathrm{q}$ or $\mathrm{q} \leq \mathrm{p})$.

\section{PRESENTATION PREFERENCES}

Students' opinions about the effect of different approaches facilitating processes of teaching and learning are obtained via a Web-based questionnaire. Some of the responses are shown in Table 1. The following notations are used: L - learners, V Instructional videos, $\mathrm{PE}$ - practical examples, IA - interactive applications, H - Kansei word 'helpful', i - increase the amount, $\mathrm{d}$ - decrease the amount, s - satisfactory. 
TABLE I: OUTCOMES.

\begin{tabular}{|c|c|c|c|c|c|c|c|c|c|c|}
\hline \multirow[t]{2}{*}{ Learners } & \multicolumn{3}{|c|}{$\begin{array}{l}\text { Instructional } \\
\text { Videos }\end{array}$} & \multicolumn{3}{|c|}{$\begin{array}{l}\text { Practical } \\
\text { Examples }\end{array}$} & \multicolumn{3}{|c|}{$\begin{array}{l}\text { Interactive } \\
\text { Applications }\end{array}$} & \multirow[t]{2}{*}{ Helpful } \\
\hline & $\mathrm{i}$ & $\mathrm{d}$ & $\mathrm{s}$ & $\mathrm{i}$ & $\mathrm{d}$ & $\mathrm{s}$ & $\mathrm{i}$ & $\mathrm{d}$ & $s$ & \\
\hline 1 & $x$ & & & $x$ & & & $x$ & & & 3 \\
\hline 2 & & & $x$ & & $x$ & & & $x$ & & 2 \\
\hline 3 & $x$ & & & $x$ & & & & & $x$ & 4 \\
\hline 4 & & & $\times$ & & & $x$ & $\times$ & & & 5 \\
\hline 5 & $x$ & & & & $x$ & & & $x$ & & 3 \\
\hline 6 & $x$ & & & & $x$ & & & $\times$ & & 2 \\
\hline 7 & & $\times$ & & $x$ & & & $x$ & & & 5 \\
\hline 8 & $x$ & & & & & $x$ & & $x$ & & 4 \\
\hline 9 & $x$ & & & & & $x$ & & & $x$ & 2 \\
\hline 11 & & & $x$ & & $x$ & & $x$ & & & 3 \\
\hline 12 & & $\times$ & & $x$ & & & & $x$ & & 3 \\
\hline 13 & & $\times$ & & $x$ & & & & & $x$ & 2 \\
\hline 14 & & & $x$ & & & $x$ & & & $x$ & 3 \\
\hline 15 & & $\times$ & & & $x$ & & & $x$ & & 2 \\
\hline 16 & & & $x$ & & $x$ & & & & $x$ & 1 \\
\hline 17 & $x$ & & & & & $x$ & $x$ & & & 2 \\
\hline 18 & & $\times$ & & & & $\times$ & & $x$ & & 3 \\
\hline 19 & $x$ & & & & & $x$ & & & $x$ & 4 \\
\hline 20 & & & $x$ & & $x$ & & & $x$ & & 4 \\
\hline 21 & & & $x$ & $x$ & & & & $x$ & & 2 \\
\hline 22 & $x$ & & & $x$ & & & & & $x$ & 2 \\
\hline 23 & & & $x$ & & $x$ & & $x$ & & & 3 \\
\hline 24 & & $\times$ & & $x$ & & & & $x$ & & 1 \\
\hline 25 & $x$ & & & & $x$ & & & & $x$ & 4 \\
\hline 26 & & & $x$ & & & $x$ & & $x$ & & 2 \\
\hline 27 & $x$ & & & & $x$ & & & $x$ & & 4 \\
\hline 28 & & & $x$ & & & $x$ & & & $x$ & 3 \\
\hline 29 & & $\times$ & & $x$ & & & & & $x$ & 3 \\
\hline 30 & & & $x$ & & & $x$ & & $x$ & $x$ & 4 \\
\hline
\end{tabular}

Here we calculate scores by where $\left|G_{i}\right|$ means the number of people in group $G_{i}$.

$$
\text { Score }_{A t t}(\text { Cat })=\sum D_{A t t}\left(\operatorname{Cat}_{G_{i}}\right) \frac{\left|G_{i}\right|}{\sum_{1}^{N}\left|G_{i}\right|}
$$

Where $\left|G_{i}\right|$ means the number of people in group $G_{i}$.

Some of the most interesting numerical values obtained after applying the score function on the data partially presented in Table 1 are Score $_{A t t}(I V$ i $)=2.14$,

$$
\begin{aligned}
& \text { Score }_{A t t}(I V d)=2.37 \quad, \quad \text { Score } A t t(I V s)=2.86 \quad \text {, } \\
& \text { Score }_{A t t}(P E \text { i })=2.93 \quad, \quad \text { Score }{ }_{A t t}(P E d)=2.52 \\
& \text { Score }_{A t t}(P E s)=2.38 \quad, \quad \text { Score }_{A t t}(\text { IA } i)=2.76 \text {, } \\
& \text { Score } \text { Att }(\text { IA } d)=2.43 \text {, Score } A t t(I A s)=2.27 \text {. }
\end{aligned}
$$

Some Type 1 and Type 2 inconsistencies in Table 1.

Type 1 - (L5, L6), (L20, L21), (L26, L27)

Type 2 - (L1, L2), (L8, L9), (L12, L13), (L15, L16), (L27, L28)

We apply methods from interval patterns to establish students' preferences for IV, PE and IA. To illustrate these preferences graphically we apply ordered sets theory. The Fig. 1 is adapted from [1].

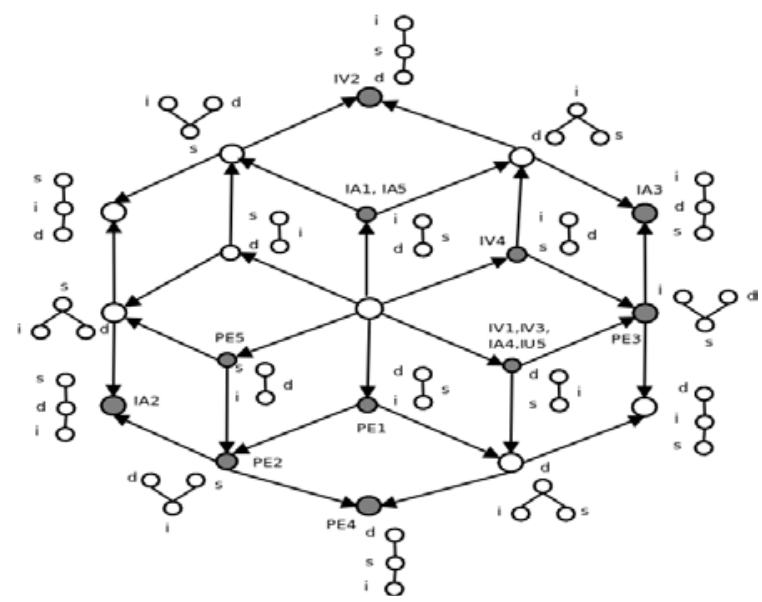

FIGURE I: ILLUSTRATION OF PREFERENCES FOR IV, PE AND IA.

First they are presented following different groups of students using each of the numbers $1,2,3,4,5$ under the Kansei word 'Helpful', see Fig.1. Shaded nodes indicate orderings extracted from the data set of students preferences. A label consisting of letters and a number is attached to each shaded node. Thus, the label PE4 attached to the lowest node in the graph in Fig. 1 means that students who use number 4 for the Kansei word 'Helpful' have different opinions about the attribute PE.

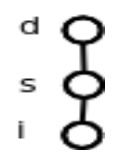

FIGURE II: ILLUSTRATION OF PREFERENCES RELATED TO PE4.

The majority states that the amount of PE should be decreased, a smaller group states that the amount of $\mathrm{PE}$ is satisfactory, and the smallest group prefers increase of PE, Fig. 2. Note that students' total preferences independent of Kansei word they use, are also as shown in Fig. 2.

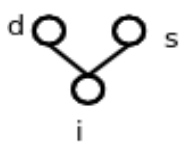

FIGURE III: ILLUSTRATION OF PREFERENCES RELATED TO PE2.

Fig.3 illustrates how students who use number 2 for the Kansei word 'Helpful' feel about the amount of PE. One group states that amount of PE should be decreased and another one states that amount of PE is satisfactory. Those two groups are of the same size. A smaller group prefers an increase of PE.

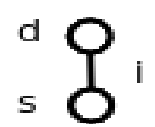

FIGURE IV: ILLUSTRATION OF PREFERENCES RELATED TO IV1, IV3, IU5 AND IA4.

Another situation is described in Fig. 4. In any of the four different cases where students who use numbers $1,3,4$, and 5 for the Kansei word 'Helpful' and refer to attributes IV, IU and IA, we observe two groups. The larger group states that 
amount should be decreased and the smaller one states that amount is satisfactory. None of them wishes increasing.

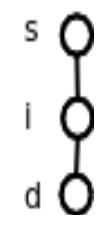

FIGURE V: ILLUSTRATION OF PREFERENCES RELATED TO IV.

Afterwards we present students preferences for each of attributes IV, PE and IA independent of Kansei word they use. The distribution of IV related preferences are shown in see Fig. 5. The distribution of $\mathrm{PE}$ related preferences are as in Fig. 3, and the ones related to IA are as in Fig. 2.

Further observations: Obviously the largest clustering of types of preferences is at the node in Fig. 4. This however is very different from students preferences in general as well as from students preferences related to any of the attributes IV, IU and IA. Orderings in Fig. 1 are arranged in a way that orderings in two nodes connected by a line differ in one type of ordering only. Thus the ordering in Fig. 3 can be used to obtain four other orderings with a single change, the node with largest clustering is directly connected to one other node only.

An interesting line of research is related to connecting learning styles and learning preferences. To which degree learning styles determine learning preferences and how such knowledge can be used for facilitating more efficient learning.

\section{CONCLUSION}

More work is needed for developing a Web based system collecting human opinions and ranking the preselected items. Additional research has to be done for evaluating learning outcomes of incorporating students' preferences into curriculum presentations. The available data set indicates that students have to be considered as individuals rather than groups when it comes to their preferences.

\section{REFERENCES}

[1] Bogart, K. P., Some social sciences applications of ordered sets. In: I. Rival, Editor, Ordered Sets, Reidel, Dordrecht, pp. 759-787, 1982.

[2] Chang, C. C., Factors influencing visual comfort appreciation of the product form of digital cameras, Int. J. Ind. Ergon. 38, (11-12), pp. 1007-1016, 2008.

[3] Ganter B. and R. Wille. R., Formal Concept Analysis, Springer, 1999.

[4] Encheva S.,Kansei Engineering in Education, IIMSS, Fronties in Artificial Intellegence and Applications, 254, pp. 281-290, 2013.

[5] Jindo T. and Hirasago K., Application studies to car interior of Kansei engineering, International Journal of Industrial Ergonomics, 19, Number 2, pp. 105-114, 1997

[6] Kato T., User modelling through unconscious interaction with smart shop, UAHCI'11: Proceedings of the 6th international conference on Universal access in human-computer interaction: users diversity -Part II, Springer-Verlag Berlin, Heidelberg, pp. 61-68, 2011

[7] Liu, S.Y. \& Lin Y.: Grey Information Theory and Practical Applications, Advanced Information and Knowledge Processing, Springer, 2006

[8] Nishino, T., Nagamachi, M., \& Tanaka, H., Variable precision bayesian rough set model and its application to Kansei Engineering. In: Trans Rough Sets, pp. 190-206, 2006

[9] Pawlak, Z., Rough Sets. International Journal of Computer and Information Sciences, 11, pp. 341-356, 1982.
[10] Lian-Yin Zhai, Li Pheng Khoo, \& Zhao-Wei Zhong: A dominance-based rough set approach to Kansei Engineering in product development, Expert Systems with Applications, 36(1), pp. 393-402, 2009.

[11] Lian-Yin Zhai, Li Pheng Khoo, \& Zhao-Wei Zhong: A rough set based decision support approach to improving consumer affective satisfaction in product design, International Journal of Industrial Ergonomics, 39, pp. 295-302, 2009.

[12] Zhang J., Wu D. \& Olson D. L., The method of grey related analysis to multiple attribute decision making problems with interval numbers, Mathematical and Computer Modelling, 42(9-10), pp. 991-998, 2005. 